\title{
Use of the Minimum Basic Data Set as a tool for the epidemiological surveillance of mesothelioma
}

\author{
Uso del Conjunto Mínimo Básico de Datos (CMBD), como instrumento \\ de vigilancia epidemológica del mesotelioma
}

https://doi.org/10.23938/ASSN.0969

L. Sánchez-Trujillo ${ }^{1,2}$, J.M. Sanz-Anquela ${ }^{1,2}$, M.A. Ortega ${ }^{1,2,3}$

\begin{abstract}
Background. Mesothelioma is a very aggressive tumor that appears after several decades of asbestos exposure. The Minimum Basic Data Set (MBDS) has been validated for the incidence of mesothelioma in Italy, but not in Spain. The objectives of this investigation are: to estimate the prevalence, incidence and mortality of mesothelioma in the Community of Madrid (CM); to evaluate the distribution of this risk within the territory; and to explore validity of the MBDS in the epidemiological surveillance of mesothelioma.
\end{abstract}

Methods. Prevalence, incidence and mortality mesothelioma rates were calculated for the $\mathrm{CM}$ from data of the MBDS (2016 and 2017), and mortality data of the Spanish National Statistics Institute (INE) for the same period. The geographical distribution of cases and deaths, and its correlation at municipal level was studied. Statistical analysis with R and Excel tools was carried out.

Results. The incidence of mesothelioma in the CM was higher than in previous years. Mortality estimated by the MBDS and calculated using INE data for 2016 were similar in the CM. The correlation between the geographical patterns of risk of mesothelioma obtained from the two sources was high $(r=0.86)$. The aggregation of cases continues in municipalities in the south, detecting the maximum risk in Aranjuez.

Conclusion. The MBDS and INE are good resources for monitoring the risk of mesothelioma. New studies that investigate the aggregation of cases in Aranjuez are required.

Keywords. Mesothelioma. Asbestos. Mortality. Epidemiological Surveillance. Geographical pattern.

\section{An. Sist. Sanit. Navar. 2021; 44 (3): 405-415}

1. Cancer Registry and Pathology Department. Hospital Universitario Príncipe de Asturias. Alcalá de Henares. Madrid. Spain.

2. Department of Medicine and Medical Specialties. Faculty of Medicine and Health Sciences. University of Alcalá. Madrid. Spain.

3. Ramón y Cajal Institute of Healthcare Research (IRYCIS). Madrid. Spain.

Received: September 22, 2020

Revised: November 7, 2020

Accepted: December 29, 2020

\section{RESUMEN}

Fundamento. El mesotelioma es un tumor muy agresivo que surge tras varias décadas de exposición al amianto. El Conjunto Mínimo Básico de Datos (CMBD), ha sido validado para conocer la incidencia del mesotelioma en Italia, pero no en España. El objetivo de este trabajo es conocer la prevalencia, incidencia y mortalidad por mesotelioma en la Comunidad de Madrid (CM), evaluar la distribución del riesgo dentro de su territorio y explorar la validez del CMBD en la vigilancia epidemiológica del mesotelioma en España.

Material y métodos. Se han utilizado los datos del CMBD de la CM con diagnóstico de mesotelioma y las causas de muerte registradas en el Instituto Nacional de Estadística (INE), durante el periodo 2016-2017. Los cálculos de tasas ajustadas, de distribución geográfica de casos y fallecidos, y de correlación del patrón geográfico a nivel municipal entre ambas fuentes (CMBD e INE), se realizaron mediante los programas $\mathrm{R}$ y Excel.

Resultados. La incidencia del mesotelioma en la CM fue más alta en 2016 y 2017 que en años precedentes. La mortalidad calculada (INE) y la estimada (CMBD) fueron similares. La correlación entre patrones geográficos de riesgo obtenidos mediante CMBD e INE fue elevada $(r=0.86)$. La agregación de casos continúa concentrándose en los municipios del sur de la CM, detectándose el máximo riesgo en Aranjuez.

Conclusiones. Tanto el CMBD como el INE representan fuentes adecuadas para monitorizar el riesgo de mesotelioma. Se precisa de nuevos estudios que expliquen la agregación de casos detectada en Aranjuez.

Palabras clave. Mesotelioma. Amianto. Mortalidad. Vigilancia epidemiológica. Patrón geográfico.

\section{Corresponding author:}

Miguel Angel Ortega

Department of Medicine and Medical Specialities

Faculty of Medicine and Health Sciences

University of Alcala

Ctra. Madrid-Barcelona, km 33'6

28871 Alcalá de Henares (Madrid)

Spain

E-mail: miguel.angel.ortega92@gmail.com 


\section{INTRODUCTION}

Mesothelioma is a neoplasm that originates in the cells that line serous cavities. The most frequent location of mesothelioma is the pleura, with pleural mesothelioma comprising up to $80 \%$ of cases ${ }^{1}$. Mesothelioma occurs mainly in elderly patients after decades of exposure to asbestos $^{2}$. The magnitude of the risk of mesothelioma is directly dependent on the level of exposure to asbestos; while minimal and continuous or brief and intense exposures may result in the development of mesothelioma. The nature and morphology of asbestos fibers also has an influence. Cumulative exposure level of at least 0.1 fibers/mL-year is considered sufficient to produce mesothelioma ${ }^{3}$.

Mesothelioma is a rare tumor but it is only the tip of the iceberg of asbestos-related diseases (ARDs), representing a serious public health problem ${ }^{3}$. The intrinsic carcinogenicity of asbestos is compounded by its high capacity to alter the clearance mechanisms of the respiratory tract. Consequently, other agents are retained, forming a highly carcinogenic cocktail. The risk of developing mesothelioma, far from being reduced with the passage of time, increases and continues for more than 40 years after exposure ${ }^{4,5}$. It is suspected that other inflammation-based nonmalignant pathologies may also be related to exposure to this carcinogen, such as chronic obstructive pulmonary disease (COPD), atherosclerosis and autoimmune diseases ${ }^{3}$. Of the total mesothelioma deaths that occur in the world, $56 \%$ occur in Europe. The majority of European countries that have historically used asbestos have high mortality rates due to mesothelioma; in turn, the rate of ARDs is proportional to the tons of asbestos consumed in the preceding decades.

For large industrialized countries, cancer resulting from asbestos exposure represents a problem due to the high morbidity and mortality involved. ARDs impose a high cost on health systems, they are responsible for high morbidity with a reduced life expectancy and have a large impact on pa- tient quality of life. Occupational exposure can extend beyond asbestos workers, applying to all workers who are involved in the processing and final destination of the material as well as to their family members who live in the home, as asbestos fibers can be carried in the clothing and hair of workers, exposing relatives to mesothelioma development ${ }^{6}$. Due to the high latency from exposure to the appearance of mesothelioma, it is expected that mesothelioma cases and deaths will continue to increase $\mathrm{e}^{7,8}$. Given the low frequency of mesothelioma and its close link to asbestos, this tumor is considered a sentinel tumor, a marker of asbestos exposure ${ }^{2,8}$. Because of its low survival, mortality from mesothelioma can be used to estimate its incidence and therefore the overall burden of the disease $\mathrm{e}^{9,10}$.

Asbestos is a mineral, and therefore, geological soils rich in any of its varieties represent a threat to the health of the population settled in these soils. Given that asbestos is present in many types of industries, it is worth asking whether exposure can also occur with the contaminants that these industries discharge in the geographical area where they are located ${ }^{11,12}$. In this sense, the studies conducted by López-Abente et al. ${ }^{13}$ and Tarrés et al. ${ }^{14}$ detected a higher risk of pleural mesothelioma in residential areas near industrial sources of asbestos. It seems that the distance from residential areas to industries that use asbestos and wind direction influence the development of pleural mesothelioma ${ }^{14}$. The use of spatial regression models can be useful when evaluating the impact of exposure to asbestos $^{11}$. According to previous studies, non-occupational exposure to asbestos of any type increases the relative risk (RR) of mesothelioma ${ }^{12,15,16}$.

The Minimum Basic Data Set (MBDS) in Spain has been operating since 1990. It collects information related to hospital discharges so it can provide data about the specialized sanitary activity of hospitals and the sanitary activity in outpatients clinics. The MBDS has been validated as a tool of epidemiological surveillance of cancer ${ }^{17}$, and also for the incidence of mesothelioma in Italy, but not in Spain ${ }^{18}$. 
The aim of this study was to determine whether the combined analysis of the MBDS and Statistical Bulletins of Death (SBDs) recorded in the Spanish National Statistics Institute (Instituto Nacional de Estadistica - INE) is an effective tool for monitoring the risk of mesothelioma. The setting chosen is a high-population region of Spain, the Community of Madrid (CM), which lacks a population-based cancer registry (PBCR).

\section{METHODS}

This is a descriptive epidemiological study that used data from three sources: the MBDS for 2016 and 2017 of the CM; the microdata files from the INE for deaths in 2016 and 2017; and the CM 2017 population census available on the INE website ${ }^{19}$. The MBDS files for 2016 and 2017 of the CM were obtained via the pertinent request mechanism from the General Directorate of Public Health at the Ministry of Health of the CM. The files were provided in .csv format with anonymized identifying patient codes, the month and year of birth and the date of each hospital discharge, as well as codes for the municipality of residence for municipalities with more than 10,000 inhabitants, following the current legal data protection framework. Each record in the MBDS is a hospital stay, so one patient may have several stays. The anonymized identifying patient code is necessary to check duplicate cases. Although the files provided cover all the care activities of public and private healthcare centers located in the CM, both hospital and extrahospital, only the data of patients with a mesothelioma diagnosis code (C45) were provided, so we did not have control of the denominator. The MBDS file includes International Classification of Diseases $10^{\text {th }}$ revision (ICD-10) codes in 21 fields. There are also 22 fields for procedure codes that were not explored.

Using the pertinent request mechanism, supported by the aims of our study as a justification, we sent a request to the INE to provide the microdata files corresponding to the SBDs that include multiple causes of death for the 2016-2017 period. All the mor- talities residing in the $\mathrm{CM}$ were extracted. The deceased persons with the $\mathrm{C} 45$ code in any of the multiple causes of death (basic cause and immediate, intermediate and fundamental causes and of other processes), were extracted separately. Due to the data protection law, deceased the residents of municipalities with less than 10,000 inhabitants did not have their municipality code included in the received files. The microdata type files were provided by the INE in .txt format in chains of 230 characters with a detailed explanation of the design for their proper analysis. The codes for the CM municipalities were obtained from the INE website $^{19}$.

In both series (MBDS cases and INE deaths) the selection criteria was the presence of code $\mathrm{C} 45$, specific for mesothelioma in the ICD-10. We checked the five different sites: $45.0=$ mesothelioma of pleura, $\mathrm{C} 45.1=$ mesothelioma of peritoneum, $\mathrm{C} 45.2=$ mesothelioma of pericardium, C45.7 = mesothelioma of other specified sites, and C45.9= mesothelioma of unspecified sites. This control had two objectives: to calculate the proportion of pleural mesotheliomas with respect to other known sites and to evaluate the quality of the coding for each of the sources (MBDS and INE), assuming that the exclusive use of codes C45.7 and C45.9, in the absence of other more precise site codes, represented a marker of poor quality coding. To this end, two files with 174 cases and 149 deaths, respectively, were developed in which, in addition to the case/ death identification code, five fields that control the $\mathrm{C} 45$ code type were incorporated. Figure 1 shows a clarifying algorithm of MBDS and INE data exploitation.

The study variables in both series, MBDS (cases) and INE (deaths), were as follows: 1distribution of diagnoses of mesothelioma in the CM by sex and five-year age group (21 groups); 2- prevalence of mesothelioma in the CM in 2016 and 2017; 3- incidence of mesothelioma in the $\mathrm{CM}$ in 2017; 4- mortality from mesothelioma in the CM in 2016; 5- geographic distribution of cases and deaths according to the municipality of residence codes of the patients; and 6- correlation of the municipal geographic pattern 


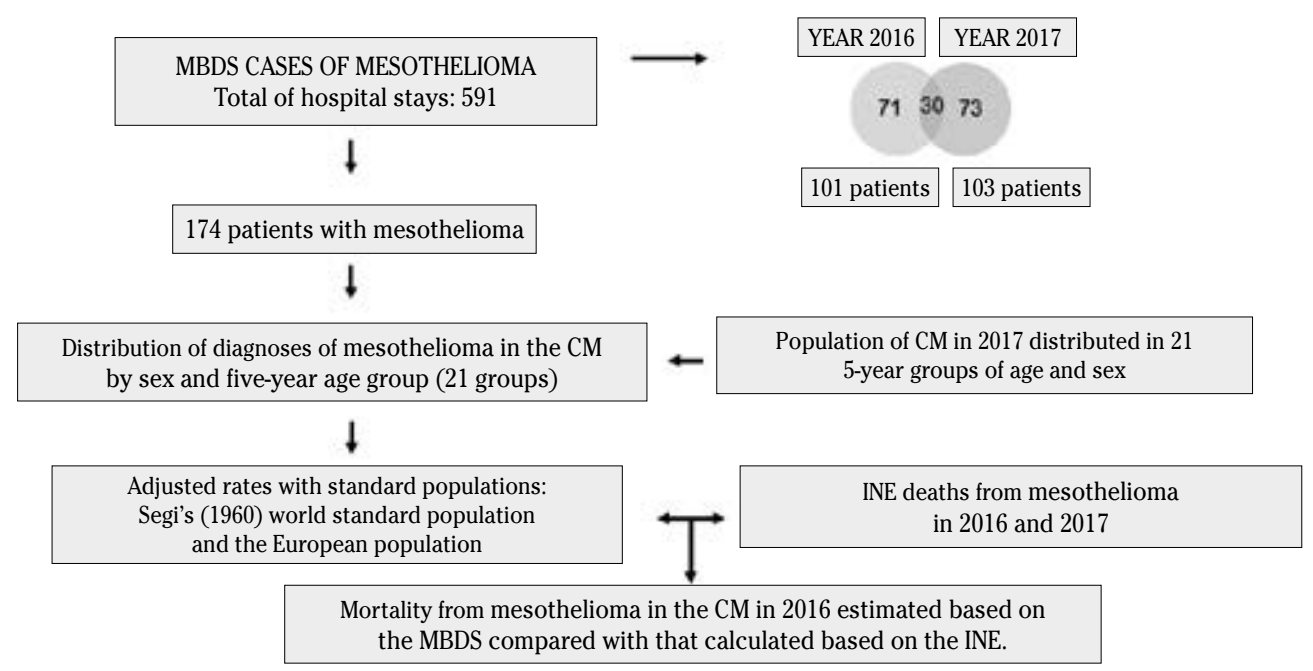

CM: Community of Madrid.

Figure 1. Algorithm of Minimum Basic Data Set (MBDS) and the Spanish National Statistics Institute (INE) data exploitation.

of risk obtained with the MBDS cases with that obtained with the INE deaths for the same period of 2016-2017. Mortality rate (and confidence interval at 95\%, 95\% CI) from mesothelioma in the CM was estimated as per the MBDS and compared with the one calculated according to the INE. Comparison was only possible for 2016 , assuming that those patients registered in the MBDS in 2016 who were not listed in 2017 had died.

To determine the geographical pattern of risk of mesothelioma within the $\mathrm{CM}$, the eight municipalities with more than 10,000 inhabitants with at least five registered cases of mesothelioma in the MBDS were selected. These data were compared with the deaths in the same period (2016-2017) of patients residing in those eight municipalities. A scatter-plot was developed, the Pearson correlation coefficient (r) was calculated, and a risk map was prepared with the Standardized Mortality Ratio (SMR) from INE data.

Data from both files, MBDS (cases) and INE (deaths), were analyzed using the $\mathrm{R}$ statistical package and programming language. The Microsoft Excel office suite was also used. This study was evaluated and ap- proved by the Research Ethics and Animal Experimentation Committee of University of Alcala under code CEIG/HU/2018/35 on October 11, 2018.

\section{RESULTS}

The MBDS series included 174 unique patients as data was provided with a unique identifying number that eliminates duplicate patients (120 men and 54 women), of whom 113 men and 53 women lived in municipalities with more than 10,000 inhabitants. In 2016, there were 258 hospital admissions and stays of 101 patients. In 2017, there were 333 hospital admissions and stays of 103 patients. Thirty patients were present in both years, and the number of patient incidents in 2017 was 103 - 30 patients $=73$ patients. It was assumed that the 71 patients admitted in 2016 who were not admitted in 2017 died.

In this series, 3,539 ICD-10 codes were detected, of which 588 were unique codes. There were five different assigned C45 codes and the distribution of cases by these mesothelioma sites were: for pleural (C45.0), 125 patients, unspecified (C45.9), 43 patients, 
Table 1. Prevalence rates of mesothelioma in 2016 and 2017, and incidence rates of mesothelioma in the Community of Madrid according to the Minimum Basic Data Set data in 2017

\begin{tabular}{|c|c|c|c|c|c|c|}
\hline & \multicolumn{4}{|c|}{ Prevalence } & \multirow{2}{*}{\multicolumn{2}{|c|}{$\begin{array}{c}\text { Incidence } \\
2017\end{array}$}} \\
\hline & \multicolumn{2}{|c|}{2016} & \multicolumn{2}{|c|}{2017} & & \\
\hline & Men & Women & Men & Women & Men & Women \\
\hline Cases/100,000 inhabitants & 68 & 33 & 77 & 26 & 52 & 21 \\
\hline \multicolumn{7}{|l|}{ Adjusted rate (SE) } \\
\hline to world SP & $1.09(0.15)$ & $0.53(0.11)$ & $1.16(0.14)$ & $0.32(0.07)$ & $0.77(0.12)$ & $0.24(0.06)$ \\
\hline to European SP & $1.69(0.21)$ & $0.70(0.13)$ & $1.84(0.22)$ & $0.47(0.10)$ & $1.23(0.18)$ & $0.36(0.09)$ \\
\hline$\%$ Accumulated risk (0-74) & 0.12 & 0.07 & 0.13 & 0.05 & 0.09 & 0.03 \\
\hline Adjusted truncated rate (35-64) & 0.13 & 0.14 & 0.07 & 0.00 & 0.03 & 0.00 \\
\hline Life years potentially lost & 117.50 & 95.00 & 160.00 & 19.00 & 104.00 & 15.50 \\
\hline Mean age of patients & 70.99 & 67.48 & 71.57 & 72.46 & 71.58 & 73.52 \\
\hline Range & $5-90$ & $19-97$ & $39-89$ & $56-86$ & $39-89$ & $56-86$ \\
\hline Standard deviation & 12.37 & 14.16 & 10.39 & 8.19 & 10.44 & 8.59 \\
\hline Population men (2017): & \multicolumn{6}{|c|}{3.115 .522} \\
\hline Population women (2017): 3.3 & \multicolumn{6}{|c|}{3.391 .662} \\
\hline
\end{tabular}

SE: standard error; SP: standard population.

other unspecified sites (C45.7), 16 patients, peritoneum (C45.1), 16 patients and pericardium (C45.2), 3 patients. Assuming that in 32 patients a specific site of mesothelioma was not provided, the percentage of MBDS records with poor mesothelioma coding quality was $18.39 \%$. Of the 143 patients with a known mesothelioma site, 125 had pleural mesothelioma; thus, this site represents $87.41 \%$ of the coded sites.

The mean age of patients was 70.78 years old (SD: 11.94; range: 5-97). In men $(\mathrm{n}=120)$, the mean age was 71.24 years old (SD: 11.58 ; range: 5-90) whereas in women $(n=54)$ the mean age was 69.83 years old (SD: 12.65; range: 19-97).

From the INE data series, only 137 out of the 149 deaths from mesothelioma had $\mathrm{C} 45$ as the basic cause of death. In 12 deaths, the $\mathrm{C} 45$ code was found in the intermediate or fundamental causes, but not as a basic cause. The distribution of deaths for the different $\mathrm{C} 45$ codes sites was as follows: C45.0 (mesothelioma of pleura), 72 deaths (52.55\%); C45.9 (mesothelioma of unspecified site), 62 deaths (45.26\%); C45.7 (mesothelioma of other specified sites), 9 deaths (6.57\%); and C45.1 (mesothelioma of peritoneum), 6 deaths (4.38\%). In $97.44 \%$ of the deaths with a known site, this was pleural.

A specific site of mesothelioma was not found in 71 deceased patients. The percentage of INE records with poor mesothelioma coding quality was $47.65 \%$, while that for the MBDS series was $18.39 \%$.

Table 1 shown prevalence rates in 2016 and 2017, and incidence rates of mesothelioma in the CM according to MBDS data in 2017.

Mortality rates $(95 \% \mathrm{Cl})$ of mesothelioma in the CM according to MBDS data in 2016 were showed in table 2 . From the INE microdata file, the mortality crude rate per 100.000 population, the adjusted rate (with SE) for world and European SP, accumulated risk (074), life years potentially lost, mean age at death, standard deviation (SD), and range of patients who died in 2016 was calculated. In 2016 , the mortality rate in men adjusted to European Standard Population was 1.25 and the mortality rate in women was 0.32 .

The comparison between the MBDS estimated mortality and the INE calculated mortality for 2016 is shown also in table 2 . Mortality rates for men between the two sources were very similar (MBDS and INE), but mortality rates for women were overestimated from MBDS data in relation the 
Table 2. Mortality rates $(95 \% \mathrm{CI})$ of mesothelioma in the Community of Madrid in 2016

\begin{tabular}{|c|c|c|c|c|}
\hline & \multicolumn{4}{|c|}{ Mortality (95\%CI) 2016} \\
\hline & \multicolumn{2}{|c|}{ MBDS } & \multicolumn{2}{|c|}{ INE } \\
\hline & Men & Women & Men & Women \\
\hline Deaths/100,000 inhabitants & 43 & 28 & 56 & 19 \\
\hline \multicolumn{5}{|l|}{ Adjusted rate (SE) } \\
\hline to world SP & $0.70(0.12)$ & $0.44(0.10)$ & $0.74(0.08)$ & $0.22(0.03)$ \\
\hline to European SP & $1.06(0.17)$ & $0.58(0.12)$ & $1.25(0.17)$ & $0.32(0.08)$ \\
\hline$\%$ Accumulated risk (0-74) & 0.08 & 0.05 & 0.08 & 0.07 \\
\hline Life years potentially lost & 61.50 & 88 & 76 & 54 \\
\hline Mean age of patients & 70.65 & 67.39 & 75.02 & 74.32 \\
\hline Range & $5-90$ & $19-97$ & 24-95 & $40-87$ \\
\hline Standard deviation & 13.43 & 15.29 & 12.29 & 12.08 \\
\hline Male population (2017): & 3.115 .522 & & & \\
\hline Female population (2017): & 3.391 .662 & & & \\
\hline
\end{tabular}

calculated rates from INE. In any case, the overestimation was not statistically significant $(95 \%$ CI European adjusted rates MBDS: 0.34-0.82, and INE: 0.48-0.16).

The geographical pattern of risk of mesothelioma within the CM highlighted eight municipalities that registered at least five cases of mesothelioma in the MBDS. The table 3 shows the crude rates of mesothelioma cases / 100,000 inhabitants according to the MBDS and of the number of cases and deaths / 100,000 inhabitants according to the INE, for the full period $2016-2017$. These data are shown for each of the mu- nicipalities with more than 10,000 inhabitants and with at least five registered cases of mesothelioma in the MBDS.

A scatter-plot was obtained from the crude rates of each of the eight locations (Fig. 2); the Pearson correlation coefficient (r) was calculated to be 0.857 . A risk map with the SMR according to the INE data was drawn up (Fig. 3); municipalities with five or more detected cases are represented in colors other than green. Most mesothelioma cases showed an aggregation in municipalities located in the south, especially Getafe and Aranjuez.

Table 3. Rate of mesothelioma cases and deaths in 2016-2017 for eight municipalities of the Community of Madrid

\begin{tabular}{lcc}
\hline Municipality & MBDS & INE \\
\hline Aranjuez & Cases / $\mathbf{1 0 0 , 0 0 0}$ inhabitants & Deaths / 100,000 inhabitants \\
Getafe & $5(8.59)$ & $6(10.31)$ \\
Leganés & $13(7.29)$ & $16(8.97)$ \\
Madrid & $9(4.79)$ & $6(3.20)$ \\
Fuenlabrada & $83(2.61)$ & $66(2.07)$ \\
Coslada & $7(3.60)$ & $4(2.05)$ \\
Alcorcón & $5(6.02)$ & $1(1.20)$ \\
Alcalá de Henares & $6(3.57)$ & $2(1.19)$ \\
\hline
\end{tabular}

MBDS: Minimum Basic Data Set; INE: Spanish National Statistics Institute. 


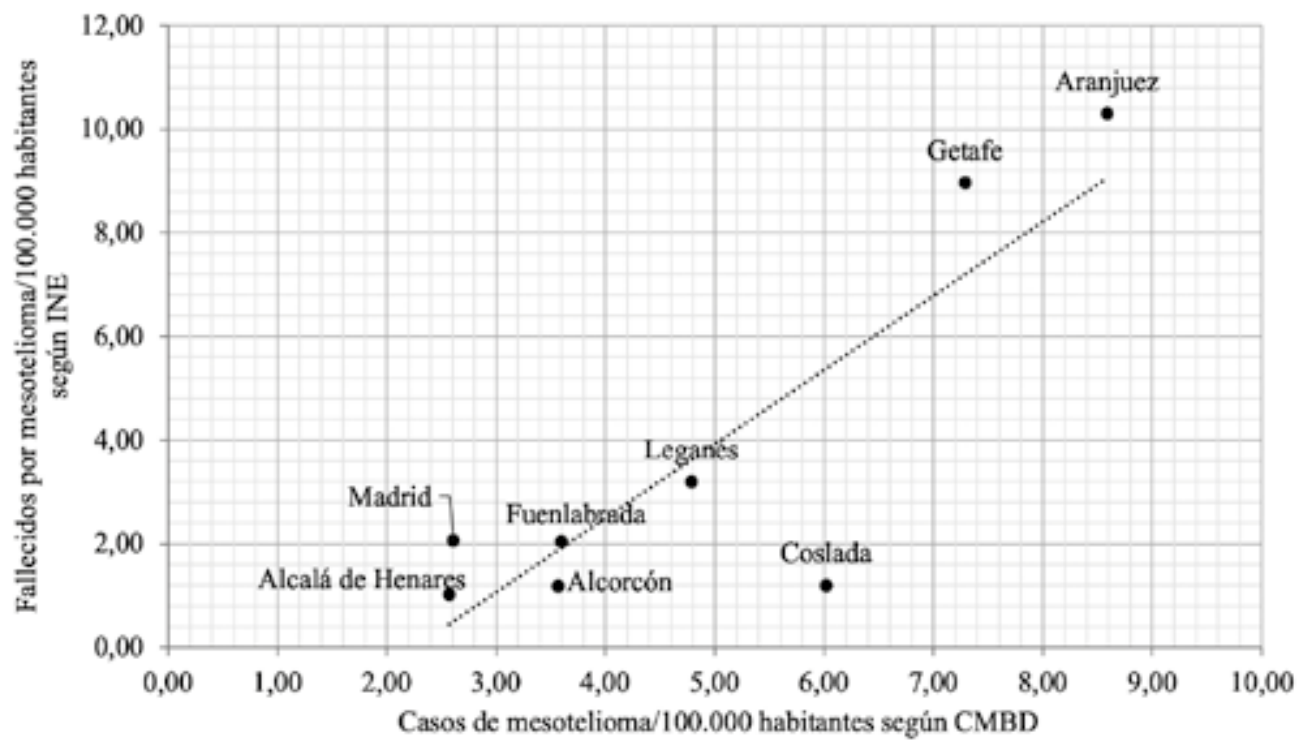

Figure 2. Municipalities of the Community of Madrid with five or more cases detected in the MBDS. Correlation between crude rates for cases and deaths per 100,000 inhabitants in the whole period (20162017). Pearson correlation coefficient $(r)=0.857$.

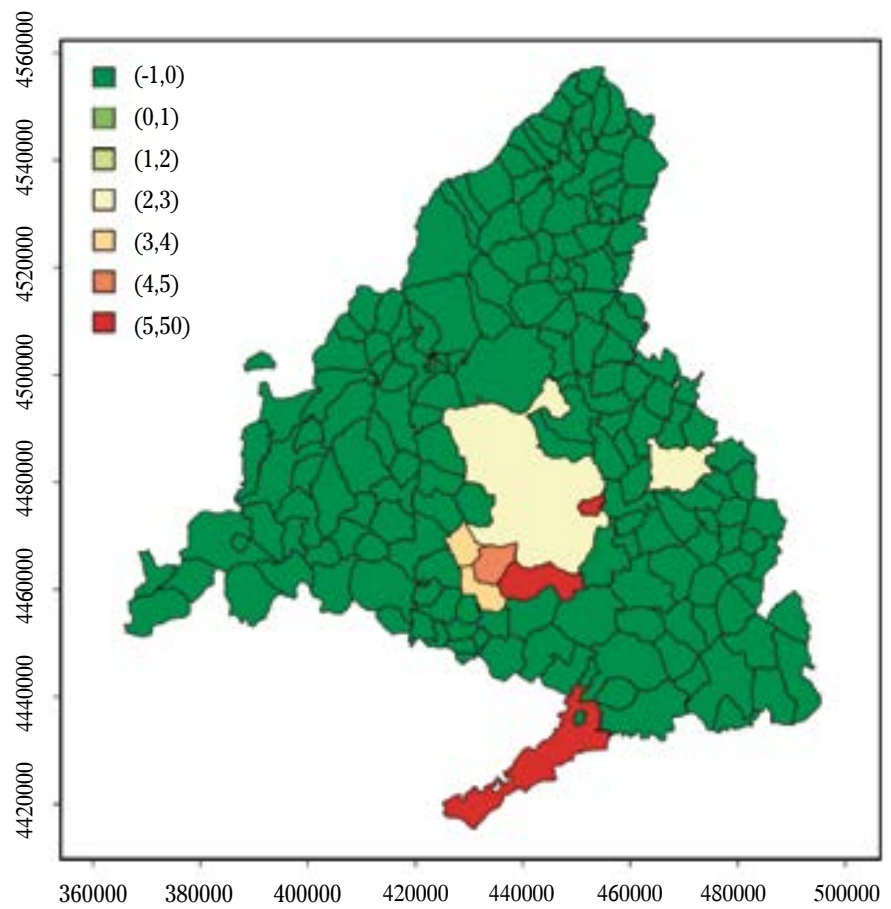

Figure 3. Geographic distribution of the eight municipalities of the Community of Madrid with the highest mesothelioma risk in the whole period (2016-2017). Standard mortality ratio in brackets. 


\section{DISCUSSION}

The lack of information on geographic areas not covered by PBCRs translates into an underreporting of cancer ${ }^{20}$. In Spain the $\mathrm{CM}$ is still one of these areas, and the MBDS could help to estimate the incidence of certain cancers, including mesothelioma. With the exception of incidence estimations from local series of cases ${ }^{14}$, no incidence of mesothelioma rates were known in Spain until now, with only mortality data being available $^{13}$. Previous studies have validated the MBDS as a tool for epidemiological surveillance of cancer in general ${ }^{21}$ improving the information in PBCRs ${ }^{22}$. The MBDS has been used previously in the study of mesothelioma incidence in Italy but not in Spain, and thus, our study is a pioneering one in this regard. Italy has a National Registry of Mesotheliomas, and therefore the MBDS has been validated properly there ${ }^{18}$. In the $\mathrm{CM}$, the only alternative to validating the MBDS as an instrument of epidemiological surveillance of mesothelioma is the SBDs recorded by the INE. The unit of the MBDS is the hospital discharge report, while the unit of the mortality registry of the INE is death. A patient can only die once but can be admitted to a hospital several times. It is therefore essential for a unique and anonymous patient identifier code number to be assigned during the processing of the MBDS data by the management unit. This process of anonymization is complex when large hospital discharge figures are used and is not exempt from errors.

The 2017 population censuses for the $\mathrm{CM}$ available on the INE website ${ }^{19}$ were used to calculate the adjusted rates. Following the direct standardization method ${ }^{23}$, calculations were carried out for two standard populations: Segi's (1960) world standard population and the European population. Segi's world population was chosen instead of the WHO (2000) world population ${ }^{23}$ because a large number of studies continue to use Segi's world population and because we could not compare our rates with rates published before 2000 if we had chosen the 2000 WHO standard world population. In turn, since the 2000 WHO standard popula- tion has an age structure that is intermediate between Segi's world and the European populations, having both rates allowed us to compare our rates to a certain extent with rates published exclusively with the 2000 WHO world standard population.

Rincón et al. studied mesothelioma deaths in the CM corresponding to the 1991-1999 period and calculated adjusted mortality rates (European standard population) of 0.97 for men and 0.3 for women ${ }^{24}$. These rates are significantly lower than those calculated in our series for 2016. The finding is in line with the predictions made in a 2013 study by López-Abente et al., according to which mesothelioma mortality rates in Spain would continue to increase at least until 2020 due to the birth cohort effect, given that the occupational exposure to asbestos was significantly lower only in men born after $1960^{25}$. In the INE series of 149 deaths analyzed for the present study, 91.95\% were born before 1960; therefore, it is expected that mortality will continue to increase due to the high weight that the birth cohort effect continues to have. These results reflect that exposure to asbestos has and will continue to have consequences in the coming years until the complete disappearance of the cohort of exposed individuals, at least until 2040 (in that year, those born in 1960 will be 80 years old). According to the study ${ }^{25}$, the prediction of the magnitude of mortality from mesothelioma in Spain is lower than that in other European countries. At the same time, another study warned of possible underdiagnosis of mesothelioma in Spain ${ }^{26}$. In our study, the percentage of the deceased (INE) lacking an specific site code for mesothelioma duplicate the percentage of the MBDS cases, which means that MBDS data can be of better quality than the SBDs of the INE. This would be one more reason to use the MBDS as an instrument for the epidemiological surveillance of mesothelioma.

The study of Rincón et al. ${ }^{24}$ on mortality from mesothelioma in the CM detected a large risk difference among municipalities and districts in the 1991-1999 period. The study identified a higher concentration of deaths in the more industrialized south- 
east zone ${ }^{24}$. In our study, we did not have access to postal codes, but the hospitals in southern Madrid in our MBDS series are those with the greatest activity related to the diagnosis and treatment of mesothelioma. Additionally, the largest aggregation of cases is concentrated in the municipalities of the southern zone. A study conducted by Odgerel et al. covers the period from 1994 to 2014, with data from more than 230 countries showing that the incidence of and mortality rates for mesothelioma have increased over time ${ }^{9}$. In Spain, López-Abente et al. studied the distribution of mortality from mesothelioma (pleural cancer) at the municipal level throughout the Spanish territory during the 1989-1998 period based on the basic cause of death in the SBDs ${ }^{27}$. The representation of the smoothed relative risk of mortality by mesothelioma on the map of Spain highlights the areas where there is greater exposure to asbestos. The preparation of maps based on municipal analysis appears to be a useful tool for the epidemiological surveillance of mesothelioma and a method for estimating asbestos exposure ${ }^{27}$. In this context, in our study Aranjuez was the municipality with the highest cases and deaths per 100.000 inhabitants along the 2016-2017 period and this could be related with factories using asbestos in the past placed in that area. A study by Crosignani et al. for the 1990-1998 period in Italy found that the MBDS not only aids in determining the cases of occupational cancer detected by PBCRs but also helps to identify the industries associated with such occupational exposure $^{28}$.

Some limitations in our study should be mentioned. The change from CIE-9 and CIE-O-3 classification to CIE-10 could mean that codifying might not be sufficiently accurate as codifying personnel need to bear in mind the new codes for mesothelioma. Also, the number of cases of mesothelioma in municipalities under 10.000 habitants (only $5 \%$ of the total of municipalities) entail a loss of information about risk in those small geographic areas, so more studies should be conducted in order to resolve this limitation. Also, some strengths of our study are the good quality of structure and design of microdata provided by INE, from which we can also know the total amount of deaths in the period of our study. MBDS provides excellent and more complete data about diagnosis and particularly about location of mesothelioma, and this data can be easily exploded.

The CM does not have a PBCR, so the MBDS and SBDs of the INE are practically the only available sources. Validity of the combined use of the MBDS / INE as an epidemiological surveillance tool for mesothelioma is based on the homogeneity of data between the two sources. In this study, the first approximation was performed by comparing the mortality estimated by the MBDS and that calculated by the INE for 2016 (see table 2). The second approximation was based on a high correlation between the crude rates of mesothelioma/100,000 inhabitants according to the MBDS and deaths from the INE, for the full period $2016-2017$ in the eight municipalities with at least five cases of mesothelioma in the MBDS (see table 3 and figure 2). The only study that used the MBDS for the detection of mesothelioma cases collected data from an Italian region that has a PBCR. In Italy, the MBDS has been successfully validated in the epidemiological surveillance of mesothelioma using the PBCR as a reference ${ }^{20}$. In the $\mathrm{CM}$, this was not possible, but the similar mortality rates detected for 2016 with both sources (MBDS and INE) and the high correlation in the aggregation of cases and deaths obtained between the two sources $(r=0.86)$ suggest that in Spain, the MBDS is an important resource to exploit for epidemiological studies of mesothelioma risk.

In conclusion, mortality rates from mesothelioma in the CM in 2016 were higher than the ones previously registered. The geographical risk pattern continues to be focused on the more industrialized municipalities of the south. The aggregation of deaths in some of the municipalities in the southern zone was already known. The maximum aggregation of cases and deaths during 2016 and 2017 in Aranjuez (hitherto undetected municipality in the southern zone) is a new finding that requires further investigation. The MBDS is an effective 
instrument for monitoring cancer risk in general and mesothelioma in particular, providing good estimators of incidence and prevalence. The SBDs of the INE are also crucial for determining the mortality rates and increasingly incorporate more information of interest associated with death. Both sources, the MBDS and INE mortality, are complementary in the epidemiological surveillance of mesothelioma. The current use of the ICD-10 in both sources and the fact that their data are available with approximately one year of lag, should encourage future research in this field.

\section{REFERENCES}

1. Lacourt A, Gramond C, Rolland P, Ducamp S, Audignon S, Astoul P et al. Occupational and non-occupational attributable risk of asbestos exposure for malignant pleural mesothelioma. Thorax 2014; 69: 532-539. https://doi. org/10.1136/thoraxjnl-2013-203744

2. Gilham C, Rake C, Burdett G, Nicholson AG, Davison L, Franchini A et al. Pleural mesothelioma and lung cancer risks in relation to occupational history and asbestos lung burden. Occup Environ Med. 2016; 73: 290-299. https:doi/10.1136/oemed-2015-103074

3. Dodson RF, Hammar SP. Asbestos : risk assessment, epidemiology, and health effects. Boca Ratón: CRC Press, 2011.

4. ŚwiątKowsKa B, SZESZENIA-DąbROWSKA N. Mesothelioma continues to increase even 40 years after exposure - Evidence from long-term epidemiological observation. Lung Cancer 2017; 108: 121-125. https://doi. org/10.1016/j.lungcan.2017.03.012

5. Pira E, Romano C, Violante FS, Farioli A, Spatari G, La Vecchia C et al. Updated mortality study of a cohort of asbestos textile workers. Cancer Med 2016; 5: 2623-2628. https://doi. org/10.1002/cam4.824

6. Plato N, Martinsen Ji, Sparén P, Hillerdal G, WeIDERPASS E. Occupation and mesothelioma in Sweden: updated incidence in men and women in the 27 years after the asbestos ban. Epidemiol Health 2016; 38. https://doi. org/10.4178/epih.e2016039; http://e-epih.org

7. KwAK KM, PaEk D, Hwang SS, Ju YS. Estimated future incidence of malignant mesothelioma in South Korea: Projection from 2014 to 2033. PLoS One 2017; 12: e0183404. https://doi. org/10.1371/journal.pone.0183404
8. Gasparrini A, Pizzo AM, Gorini G, Seniori CostanTini A, Silvestri S, Ciapini C et al. Prediction of mesothelioma and lung cancer in a cohort of asbestos exposed workers. Eur J Epidemiol 2008; 23: 541-546. https://doi.org/10.1007/ s10654-008-9257-z

9. Odgerel CO, Takahashi K, Sorahan T, Driscoll T, Fitzmaurice C, Yoko-O M et al. Estimation of the global burden of mesothelioma deaths from incomplete national mortality data. Occup Environ Med 2017; 74: 851-858. https:// doi.org/10.1136/oemed-2017-104298

10. Furuya S, Chimed-Ochir O, TAKahashi K, David A, TAKALA J. Global asbestos disaster. Int J Environ Res Public Health 2018; 15: 1000. http:// www.ncbi.nlm.nih.gov/pubmed/29772681

11. KRÓWCZYŃSKa M, Wilk E, PabJaneK P, OlędzKa G. Pleural mesothelioma in Poland: Spatial analysis of malignant mesothelioma prevalence in the period 1999-2013. Geospat Health 2018; 13: 667. https://doi.org/10.4081/ gh.2018.667

12. Mensi C, Riboldi L, De Matteis S, Bertazzi PA, Consonni D. Impact of an asbestos cement factory on mesothelioma incidence: Global assessment of effects of occupational, familial, and environmental exposure. Environ Int 2015; 74: 191-199. https://doi.org/10.1016/j. envint.2014.10.016

13. López-Abente G, Fernández-Navarro P, Boldo E, RAMIS R, GARCíA-PÉREZ J. Industrial pollution and pleural cancer mortality in Spain. Sci Total Environ 2012; 424: 57-62. https://doi. org/10.1016/j.scitotenv.2012.02.047

14. Tarrés J, Alberti C, Martínez-Artés X, Abós-HeRRÀndiz R, Rosell-Murphy M, García-Allas I et al. Pleural mesothelioma in relation to meteorological conditions and residential distance from an industrial source of asbestos. Occup Environ Med 2013; 70: 588-590. https://doi. org/10.1136/oemed-2012-101198

15. Xu R, Barg FK, Emmett EA, Wiebe DJ, Hwang W-T. Association between mesothelioma and non-occupational asbestos exposure: systematic review and meta-analysis. Environ Heal 2018; 17: 90. https://doi.org/10.1186/ s12940-018-0431-9

16. Lacourt A, Gramond C, Rolland P, Ducamp S, Audignon S, Astoul $P$ et al. Occupational and non-occupational attributable risk of asbestos exposure for malignant pleural mesothelioma. Thorax 2014; 69: 532-539. https://doi. org/10.1136/thoraxjnl-2013-203744

17. Fernández-Navarro P, López-Abente G, SalidoCAmpos C, Sanz-Anquela JM. The Minimum Basic Data Set (MBDS) as a tool for cancer epidemiological surveillance. Eur J Intern Med 
2016; 34: 94-97. https://doi.org/10.1016/j. ejim.2016.06.038

18. Stura A, Gangemi M, Mirabelli D. Use of hospital discharge records to estimate the incidence of malignant mesotheliomas. Epidemiol Prev 2007; 31: 127-131.

19. INE. Instituto Nacional de Estadística. 2019. https://www.ine.es

20. Bernal-Delgado EE, Martos C, Martínez N, Chirlaque MD, Márquez M, Navarro $\mathrm{C}$ et al. Is hospital discharge administrative data an appropriate source of information for cancer registries purposes? Some insights from four Spanish registries. BMC Health Serv Res 2010; 10: 9. https://doi.org/10.1186/14726963-10-9

21. Vitullo F, Biagio K Di, Murgano A, Bartolomeo P Di. Hospital discharge records as data source to monitor epidemiologic indicators of hematologic malignancies in Abruzzo. Tumori 2016; 102: 258-263. https://doi.org/10.5301/ tj.5000472

22. Piscitelli P, Barba M, Crespi M, Di Maio M, SantoRIELlo A, D'AiuTo M et al. The burden of breast cancer in Italy: Mastectomies and quadrantectomies performed between 2001 and 2008 based on nationwide hospital discharge records. J Exp Clin Cancer Res 2012; 31: 96. https://doi.org/10.1186/1756-9966-31-96

23. Ahmad OB, Boschi-Pinto C, Lopez Christopher AD, Murray JL, Lozano R, Inoue M. Age stan- dardization of rates: A new WHO standard. World Health Organization. 2001. https:// www.who.int/healthinfo/paper31.pdf

24. Rincón A, Gandarillas A, Zorrilla B, León C. Mortalidad por mesotelioma en la Comunidad de Madrid, 1991-1999. En: XX Reunión Científica de la Sociedad Española de Epidemiología, Madrid. Gac Sanit 2002; 16: 75-78.

25. López-Abente G, García-Gómez M, MenéndezNavarro A, Fernández-Navarro P, Ramis R, GarCíA-PÉrez $\mathrm{J}$ et al. Pleural cancer mortality in Spain: Time-trends and updating of predictions up to 2020. BMC Cancer 2013; 13: 528. https://doi.org/10.1186/1471-2407-13-528

26. García-Gómez M, MenÉndez-Navarro A, Castañeda LóPEz R. Asbestos-related occupational cancers compensated under the Spanish National Insurance system, 1978-2011. Int J Occup Environ Health 2015; 21: 31-39. https://doi.or g/10.1179/2049396714y.0000000087

27. Lopez-Abente G, Hernández-Barrera V, Pollán M, Aragonés N, Pérez-Gómez B. Municipal pleural cancer mortality in Spain. Occup Environ Med 2005; 62: 195-199. http://dx.doi. org/10.1136/oem.2004.015743

28. Crosignani P, Massari S, Audisio R, Amendola $\mathrm{P}$, Cavuto S, Scaburri A et al. The Italian surveillance system for occupational cancers: Characteristics, initial results, and future prospects. Am J Ind Med 2006; 49: 791-798. https://doi.org/10.1002/ajim.20356 
